\title{
Retrospective analysis of rectal stenosis after anterior resections with or without stapling: rectal stapling is not a "thornless rosary"
}

\author{
Kenan Erzurumlu, Zafer Malazgirt, Ali Naki Ulusoy, Ayfer Kamalı Polat, Bulent Gungor, *Cafer Polat \\ Department of General Surgery, Medical Faculty, Ondokuz Mayls University, Samsun, Turkey
}

\begin{tabular}{|c|c|}
\hline ARTICLE INFO & ABSTRACT \\
\hline Article History & \multirow{17}{*}{$\begin{array}{l}\text { Recently, stapler anastomosis is the method of choice in low or ultra low resection for } \\
\text { rectal carcinoma. In this study, risk of rectal stricture formation after double stapling } \\
\text { colorectal anastomosis was evaluated. We here with presented an invitro investigation } \\
\text { and a retrospective analysis of } 91 \text { cases of rectal carcinoma treated by low or ultra low } \\
\text { anterior resection with hand-sewn or double-stapled colorectal anastomosis between the } \\
\text { years } 2002-2006 \text { regarding the late complication of postoperative stenosis. In in vitro } \\
\text { investigation external and internal diameters of staplers were measured. Also diameters of } \\
\text { anastomotic lines were investigated on stapled sheep intestine and low anterior resection } \\
\text { specimen of human, in vitro. External and internal diameters of } 29 \text { and } 33 \mathrm{~mm} \text { staplers } \\
\text { were found } 19.5-24 \mathrm{~mm} \text { respectively. Also diameters of anastomosis with } 29 \mathrm{~mm} \text { stapler } \\
\text { at sheep intestine and } 33 \mathrm{~mm} \text { stapler at low anterior specimen were found } 15 \mathrm{~mm} \text {, } 20 \mathrm{~mm} \\
\text { respectively.Rectal stricture was not seen in any of the patients with hand-sewn anastomoses. } \\
\text { We found postoperative stricture of the rectal anastomosis in } 11 \text { (17.2 \%) of the patients } \\
\text { treated by double-stapled group (p=0.022). The risk factors that we have investigated were } \\
\text { age and gender of the patient, location and stage of the tumour, diameter of EEA staplers, } \\
\text { and presence of neoadjuvant or adjuvant chemoradiotherapy. Although double-stapling } \\
\text { anastomosis in rectal cancers has clear technical advantages over hand-sewn technique, the } \\
\text { late complication of stenosis occurred at a significantly higher rate after this technique.Key } \\
\text { words: rectal cancer, double-stapling anastomosis, stenosis, EEA staplers. } \\
\text { J. Exp. Clin. Med., } 2010 ; 27: 20-23\end{array}$} \\
\hline 22 / 07 / 2010 & \\
\hline 27 / 07 / 2010 & \\
\hline * Correspondence to: & \\
\hline Cafer Polat & \\
\hline Ondokuz Mayis University, & \\
\hline Medical Faculty, & \\
\hline Department of General Surgery & \\
\hline Samsun/Turkey & \\
\hline e-mail: caferpolat@omu.edu.tr & \\
\hline Key Words: & \\
\hline Rectal Cancer & \\
\hline Stapling Technique & \\
\hline Rectal Stenosis & \\
\hline Circular Stapler & \\
\hline Low Anterior Resection & \\
\hline Hand-Sewn Anastomosis & \\
\hline
\end{tabular}

(C) 2010 OMU All rights reserved

\section{Introduction}

After single stapling technique was used at end-to-end low rectal anastomosing in 165 cases by Russian colleagues between the years 1967-1972, the double-stapling technique of low rectal anastomoses has been re-described in 1980, and have been advocated as the "gold standard" thereafter (Fain et al., 1975; Smith, 1981). In Fain (1975), reported his first experimental research (stapling colorectal anastomosis in dogs) with no complication. Knight et al., (1980) published the initial cases of stapler colorectal anastomosis in the USA in 1980.

The resection and anastomosis of low and ultralow rectal cancers utilizing the double-stapling technique has long been accepted as the gold standard due to its numerous advantages, including lower morbidity and mortality rates, shorter operating time, and easier handling especially during ultra-low anterior resections. The videolaparoscopic double-stapling resection and anastomosis of rectal cancers has gained popularity in the recent years.

After 1980s, the complications of double stapling for rectal carcinomas appeared in the clinical studies. Although morbidity and mortality rates are similar in hand-sewn and double-stapling techniques at colorectal anastomoses, the most important complication of doublestapling is stricture formation at the anastomotic line (Yu et al., 2000; Fingerhut et al., 1994).

In this study, we evaluated the incidence and related risk factors of stricture formation in a total of 64 cases of rectal cancers, in whom the anastomoses were accomplished by the double-stapling technique.

\section{Patients and Methods}

This study consists of two parts as in vitro investigation and retrospective clinical analysis.

Formerly, external and internal diameters of 
staplers were measured. Also diameters of anastomotic lines were investigated on stapled sheep intestine and low anterior resection specimen of human, in vitro.

Then, as we screened retrospectively the records of cases, whom had been subjected to resection and primary anastomosis due to their rectal carcinoma between the years 1983-2006, we gathered a total of 175 cases. Local ethical committee approved the study. We analysed their data according to our study protocol, in which the inclusion and exclusion criteria were well described. Those with incomplete records or lost to follow-up before three years, reoperated for any rectal lesion within three years, rectal stenosis due to recurrent disease, and those died in the first three postoperative years either due to primary disease or else were excluded from the study. Those with diverting colostomy were included in the study, only if their colostomy was closed within the first six postoperative months. However, those who have their colostomy closed at a later date or those who have never had their colostomies closed were dropped off the list. Out of 175 cases, we excuded a total of 84 cases, accordingly. We carried out this study on 91 cases of rectal carcinoma patients, whom were free of malignant disease after a minimum of three years after they had undergone low- or ultra-low anterior resection and primary anastomosis. The low rectal anastomoses have been done by either handsewn or double-stapling technique.

Patients are divided into two groups according to the methods of rectal anastomosis. Group A ( $\mathrm{Gr} \mathrm{A}$ ) consisted of 27 patients with hand-sewn anastomoses. In this group anastomoses were done by single or two-layer interrupted or continuous sutures.

Group B (Gr B) included 64 cases of doublestapled rectal anastomoses. In this group, rectal cuffs were closed by TA staplers followed by anastomosing utilizing transanal EEA staplers.

In the patients suspected stricture formation clinically was examined by sigmoidoscopy and found inability to pass a $12 \mathrm{~mm}$ - colonoscope, biopsy for histopathological research was done. Patients with neoplastic stricture formation seen, excluded from the study.

Patient's resion histopatolgreally named as fibrosis nonneoplastic stricture is included in this study. The records of the patients were evaluated retrospectively. The data including the age and gender of the patients, the location and stage of the tumour, the diameter of EEA staplers which used for the rectal anastomosing, and whether neoadjuvant or adjuvant chemoradiotherapy has been added to the treatment program were noted in all patients. The statistical analysis was accomplished in two steps. First, the risk of stricture formation was examined in both groups. Secondly, the relationship between the stricture formation and the risk factors were studied. The Z-test of two proportions was studied.

\section{Results}

In in vitro investigation, external and internal diameters of 29 and $33 \mathrm{~mm}$ staplers were found 19.5-24 mm respectively. Also diameters of anastomosis with $29 \mathrm{~mm}$ stapler at sheep intestine and $33 \mathrm{~mm}$ stapler at low anterior specimen were found $15 \mathrm{~mm}, 20 \mathrm{~mm}$ respectively (Fig 1).

\section{Analysis of groups in clinical study:}

The age, gender, and tumour stages of the patients were similar in both groups $(\mathrm{p}>0.05)$ (Table 1$)$. The average distance of tumours to the dentate line was greater in Gr A as related to that of Gr B $(\mathrm{p}<0.05)$ (Table 2).

According to the protocol, the least follow-up period after anastomoses were three years. A total of 23 patients were followed up at a minimum of 3 years. The average follow up period in Gr A and Gr B patients were $19.81 \pm 3.745$ and $5.56 \pm 3.09$ years (range 15-26 and 3-15 years), respectively. No stricure at the anastomoses was detected in Gr A. Stricture at the rectal anastomose were diagnosed in 11 patients $(17.2 \%)$ after 2-36 months postoperatively (mean $8.1 \pm 10.3$ ) in $\mathrm{Gr}$ B. The majority of them ( 8 cases, $72.7 \%$ ) occurred in the initial 2-5 month period. The risk of stricture formation was statistically significant among Gr B patients $(\mathrm{p}=0.022)$.

Table 1. The comparison of baseline parameters in both groups.

\begin{tabular}{|c|c|c|c|}
\hline & $\begin{array}{c}\text { Gr A } \\
\text { (Hand sewn) } \\
(\mathrm{n}: 27)\end{array}$ & $\begin{array}{c}\text { Gr B } \\
\text { (Double stapled) } \\
(\mathrm{n}: 64)\end{array}$ & $\mathrm{p}$ \\
\hline Age & $\begin{array}{c}59.1 \pm 12.3 \\
\text { (range } 37-80)\end{array}$ & $\begin{array}{c}62.3 \pm 12.0 \\
\text { (range 36-88) }\end{array}$ & 0.264 \\
\hline Gender F/M & $12 / 15$ & $30 / 34$ & \\
\hline \multirow[t]{3}{*}{ Tumours' stage } & $5(18.5 \%)$ & $11(17.2 \%)$ & \multirow{3}{*}{0.983} \\
\hline & $9(33.3 \%)$ & $21(32.8 \%)$ & \\
\hline & $13(48.1 \%)$ & $32(50.0 \%)$ & \\
\hline \multirow{3}{*}{$\begin{array}{r}\text { Distance to dentate line }(\mathrm{cm}) \geq 11 \\
6-10 \\
\leq 5\end{array}$} & $13(48.1 \%)$ & $22(34.4 \%)$ & \multirow{3}{*}{0.327} \\
\hline & $9(33.3 \%)$ & $32(50.0 \%)$ & \\
\hline & $5(18.5 \%)$ & $10(15.6 \%)$ & \\
\hline Stricture formation & 0 & $11(17.2 \%)$ & 0.022 \\
\hline
\end{tabular}

Gr B analysis:

Diameters of EEA staplers used for colorectal anastomosis were $\leq 29 \mathrm{~mm}$ in $49(76.6 \%)$, and $\geq 31 \mathrm{~mm}$ in $15(23.4 \%)$ cases.

Eleven patients (17.2\%) had chemotherapy, and $4(6.3 \%)$ had radiotherapy alone. A total of $36(56.3 \%)$ patients had combined chemo-radiotherapy. In $13(20.3 \%)$ cases neither chemo- nor radiotherapy was administered. None of the strictures were due to local recurrence of primary rectal cancer. Any patient with a diagnosis of recurrent disease was excluded from the study. The patients with stricturing anastomosis, in whom no tumour was found histopathologically were included in this study. Stricturing anastomoses were found in 11 cases (17.2\%). The main clinical and histopathological finding at the stricturing anastomoses were the presence of fibrosis. 
As we investigated the risk factors which would be responsible for the stricture formation at the anastomotic line, we didn't find any significant risk factor. Any of the above-mentioned parameters were found as the potential cause of the stricturing at the anastomoses. Namely, the diameter of the EEA staplers and presence or absence of chemoradiation seemed to be not influential upon stenosing ( $>0.05$ ) (Table 2). The strictures in 10 of 11 cases $(90.9 \%)$ were dilated simply by examining finger and anal dilators. In the remaining case, transanal hydrostatic dilation was utilized.

Table 2. The risk factor analysis in Gr B patients, in whom the rectal anastomoses were done by double-stapling technique.

\begin{tabular}{|l|l|l|l|l|}
\hline & Group & Group n & Stenosis n (\%) & $\mathrm{p}$ \\
\hline Age & $\leq 60$ & 19 & $4(21.1)$ & 0.594 \\
& $\geq 61$ & 45 & $7(15.6)$ & \\
\hline Gender & M & 34 & $5(14.7)$ & 0.819 \\
& F & 30 & $6(20.0)$ & \\
\hline Stage & I & 11 & $3(27.3)$ & 0.617 \\
& II & 21 & $3(14.3)$ & \\
& III & 32 & $5(15.6)$ & \\
\hline \multirow{2}{*}{ Distance to dentate line (cm) } & $\geq 11$ & 22 & $5(22.7)$ & 0.599 \\
& $6-10$ & 32 & $4(12.5)$ & \\
& $\leq 5$ & 10 & $2(20.0)$ & \\
\hline Diameter of EEA stapler (mm) & $\geq 31$ & 15 & $3(20.0)$ & 0.710 \\
& $\leq 29$ & 49 & $8(16.3)$ & \\
\hline Chemotherapy & Yes & 47 & $7(14.9)$ & 0.463 \\
& No & 17 & $4(23.5)$ & \\
\hline Radiotherapy & Yes & 40 & $9(18.4)$ & 0.186 \\
& No & 24 & $2(8.3)$ & \\
\hline
\end{tabular}

\section{Discussion}

Low anterior resection is the treatment of choice in surgery of rectal carcinoma. Because of the distal margin must be at least one $\mathrm{cm}$ far to tumour, ultra low anterior resection is considered difficult by hand sewing method. The introduction of single or double stapling techniques has added much to the ease and safety of the operation, and enabled surgeons to do more anterior resections for

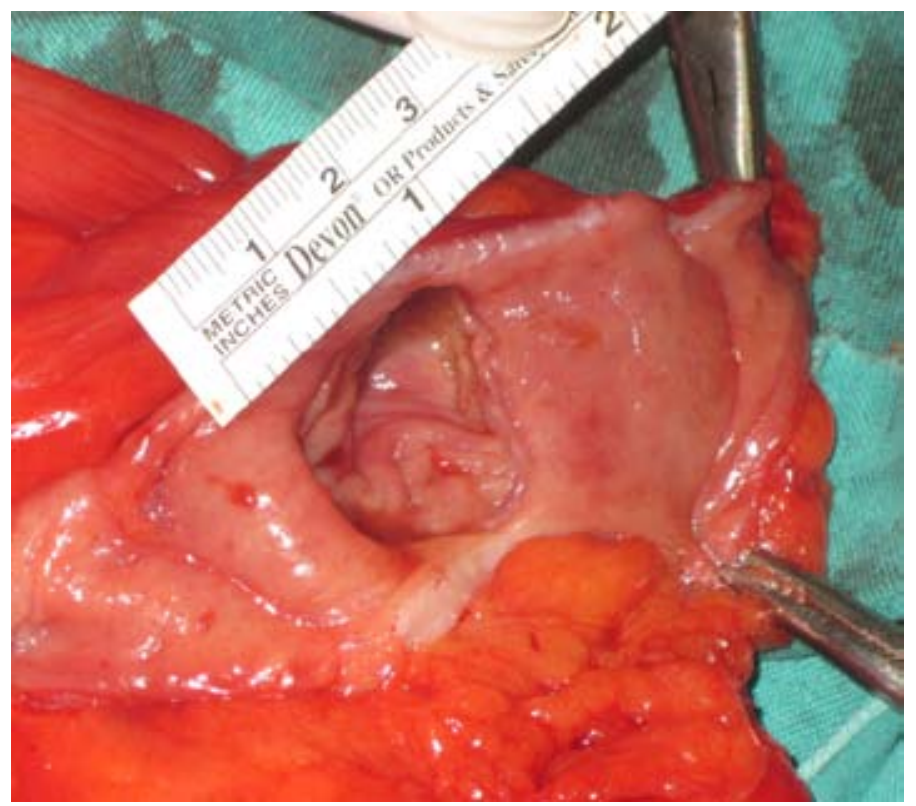

Fig 1. Internal view of $33 \mathrm{~mm}$ stapled anastomosis on low anterior resection specimen. low rectal cancers. The stapling techniques have definitely decreased the incidence of abdominoperineal resections, as well.

The incidence of primary and technique-related complications of stapling anastomosis is reportedly between 2.4-32 \% (Smith, 1981; Thiede et al., 1981; Ti et al., 1986; Petrassi et al., 1994; Shimada et al., 1996; De Salvo et al., 1997; Yu et al., 2000; Brigand et al., 2004; Pan et al., 2004; Ambrosetti et al., 2008; Sciume et al., 2008). In 1994, Fingerhut showed in a randomised clinical study that stapled anastomosis has four times more risk of stricture than hand sewn's. Similarly, in a randomised clinical study containing 622 patients of stapled and 611 hand sewn colorectal anastomosis, Lustosa et al., (2002) found in 2002 high risk of stricture and shortened operating time in the stapled group. Our rate of stenosis is corresponding to the published data.

Risk factors of stricture formation after rectal anastomosis has not yet been clear. The incidence of stenosis has been reported, however no certain risk factor has been clarified (Stahle et al., 1986; Shimada et al., 1996; Ambrosetti et al., 2008; ). Gender (Bannura et al., 2004), ischemia, radiation and defunctionalisation (McKee and Pricolo, 2008), anastomotic leakage (Thiede et al., 1981; McKee and Pricolo, 2008) have been proposed as risk factors. Graf (1991) reported in 1991 that single stapling has higher risk of stenosis than double stapling. Bannura (2004), reported that most of the strictures occur in the first four months in the postoperative period.

Although diameter of stapler still remains controversial as a risk factor of stricture formation. it is a concensus that larger devices have lesser risks. Yu et al., (2000) showed that large diameter ( $\geq 33 \mathrm{~mm}$ ) EEA stapler has lesser risk. Herein, wideness of stapler anastomosis has great importance.

On the other hand, internal diameter of stapler is approximately $1 / 4$ lesser than external's. Also applications of staplers are always on stretched intestinal segments. So, in normal status, stapled anastomoses are quite narrower than devices' diameters. In invitro part of this study, it is proved clearly. In our study, the incidence of rectal stenosis was found to be $17.2 \%$. We have seen most of the strictures in the first five months of the rectal anastomosis. We were unable to advocate any significant risk factor functional in the formation of stenosis of rectal anastomosis. This is most probably due to the rather small number of cases taking part in the study.

Clinical symptoms and findings of stenosis may easily be confused with the local recurrence of rectal cancer. An endoscopic investigation and biopsy are important diagnostic tools in the differential diagnosis of local recurrence and stenosing anastomosis. Tenesmus, difficulty in defecation, and complete obstruction may be seen in either condition. However, bleeding occurs more in local recurrence. Although rigid or flexible sigmoidoscopy with biopsy are the main diagnostic tools in the differential diagnosis, endorectal ultrasound, barium enema, computed 
tomography, and magnetic resonance imaging may all be used in confirmation of the exact diagnosis. However, endoscopy and biopsy are superior to other methods due to the facts that endoscopy enables tissue diagnosis and dilatation when feasible.

Main treatment of stenotic anastomosis in most of the cases is simple finger dilatation (Yagyu et al., 2002). The anal dilatators may be feasible in some cases (Araki et al., 2002). The dilation may be repeated when necessary. If sufficient dilatation can not be accomplished by finger or dilatator, other methods including hydrostatic dilatation, transanal incision, and restapling may be helpful (Araki et al., 2002). Shimada (1996) reported an $89 \%$ success rate after partial anastomotic resection utilizing a cutter stapler.
Kato (1997) stressed that Nd:YAG laser is effective in the treatment of postoperative rectal stenosis. In our study, we diagnosed the rectal strictures by endoscopy and biopsy, after which simple or hydrostatic dilation were used. Moderate to good results have been noted in all of 11 cases. No surgical intervention was required.

We conclude that double or single stapling techniques utilized in the anastomosis of rectal stumps after anterior resections may cause rectal stenosis, of which the most occur early in the postoperative course. We were unable to delineate factors responsible for the stenosis. We believe that larger series would have an impact on better understanding of the factors causing benign rectal stenosis after resection and stapler anastomosis of the rectum.

\section{REFERENCES}

Ambrosetti, P., Francis, K., De Peyer, R., Frossard, J.L., 2008. Colorectal anastomotic stenosis after elective laparoscopic sigmoidectomy for diverticular disease: a prospective evaluation of 68 patients. Dis. Colon. Rectum. 51, $1345-1349$.

Araki, Y., Kishimoto, Y., Sato, Y., Torigoe, S., Kido, K., Matono, K., Shirouzu, K., 2002. Transanal dilation using circular stapling for benign rectal stenosis: report of a case. Kurume Med. J. 49, 149-151.

Bannura, G.C., Cumsille, M.A., Barrera, A.E., Contreras, J.P., Melo, C.L., Soto, D.C., 2004. Predictive factors of stenosis after stapled colorectal anastomosis: prospective analysis of 179 consecutive patients. World J. Surg. 28, 921-925.

Brigand, C., Rohr, S., Meyer, C. 2004. Colorectal stapled anastomosis: results after anterior resection of the rectum for cancer. Ann. Chir. 129, 427-432.

De Salvo, L., Razzetta, F., Cagnazzo, A., Tassone, U., Arezzo, A., Mattioli, F.P. 1997. Comparison of colorectal mechanical suture techniques. Ann. Ital. Chir. 68, 381-384.

Fain, S.N., Patin, C.S., Morgenstern, L., 1975. Use of a mechanical suturing apparatus in low colorectal anastomosis. Arch. Surg. 110, 1079-1082.

Fingerhut, A., Elhadad, A., Hay, J.M., Lacaine, F., Flamant, Y. 1994. Infraperitoneal colorectal anastomosis: hand-sewn versus circular staples. A controlled clinical trial. Fr. Associations Surg. Res. Surgery. 116, 484-490.

Graf, W., Glimelius, B., Bergström Påhlman, L., 1991. Complications after double and single stapling in rectal surgery. Eur. J. Surg. 157, 543-547.

Kato, K., Saito, T., Matsuda, M., Imai, M., Kasai, S., Mito, M., 1997. Successful treatment of a rectal anastomotic stenosis by transanal endoscopic microsurgery (TEM) using the contact Nd:YAG laser. Surg. Endosc. 11, 485-487.

Knight, C.D., Griffen, F.D., 1980. An improved technique for low anterior resection of the rectum using the EEA stapler. Surguery $88,710-714$.

Lustosa, S.A., Matos, D., Atallah, A.N., Castro, A.A., 2002. Stapled versus handsewn methods for colorectal anastomosis surgery: a systematic review of randomized controlled trials. Sao Paulo Med. J. 120, 132-136.

McKee, R., Pricolo, V.E. 2008. Stapled revision of complete colorectal anastomotic obstruction. Am J. Surg. 195, $526-527$.

Pan, Z.Z., Wan, D.S., Ding, P.R., Li, L.R., Chen, G., Wu, X.J., Zhou, Z.W., Lu, Z.H., Wan, X.B., Li, C.M. 2004. Long-term result of low anterior resection with stapling devices for rectal cancer. Ai. Zheng. 23, 1508-1511.

Petrassi, A., Roncone, A., Formisani, P., Iannello, A., 1994. Results of the multicenter study (A.C.O.I. Stapler Study Group) on 420 cases of esophagojejunal and 544 cases of colorectal anastomoses. Ann. Ital. Chir. 65, 49-58.

Sciumè, C., Geraci, G., Pisello, F., Arnone, E., Romeo, M., Modica, G., 2008. Mechanical versus manual anastomoses in colorectal surgery. Personal experience. G. Chir. 29, 505-510.

Shimada, S., Matsuda, M., Uno, K., Matsuzaki, H., Murakami, S., Ogawa, M., 1996. Anew device for the treatment of coloproctostomic stricture after double stapling anastomoses. Ann. Surg. 224, 603-608

Smith, L.E. 1981. Anastomosis with EEA stapler after anterior colonic resection. Dis. Colon Rectum. 24, $236-242$.

Stahle, E., Pahlman, L., Enblad, P., 1986. Double stapling technique in the management of rectal tumours. Acta. Chir. Scand. $152,743-747$.

Thiede, A., Jostarndt, L., Troidl, H., Poser, H.L., Bertz, U., Hamelmann, H., 1981.Value of circular mechanical colon and rectum anastomosis. Prospective study of 91 patients. Chirurg. 52, 30-35.

Ti, T.K., Rauff, A., Goh, H.S. 1986. Anterior resection using the circular stapling instrument: a Singapore experience. Aust. N. Z. J. Surg. 56, 919-922.

Yagyu, T., Yamamoto, T., Mochizuki, H., 2002. Regular finger dilation for preventing anastomotic stenosis after low anterior resection. Surg. Today. 32, $220-223$.

Yu, B., Li, D., Zheng, M., Shen, Y., Wang, H., 2000. Total meso-rectal excision in low anterior resection with double stapling technique. Zhonghua Wai Ke Za Zhi. 38, 496-498 